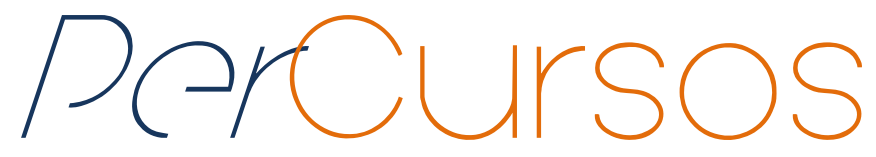

\title{
Leitura, gramática e escrita: tríade necessária para o ensino de Língua Portuguesa na construção do gênero entrevista com abordagem sobre variação linguística
}

\begin{abstract}
Resumo
Este artigo tem como propósito refletir sobre o ensino de gramática, leitura e escrita nas aulas de língua portuguesa; para isso, apresenta uma proposta de sequência didática (SD) com abordagem sobre a produção do gênero textual entrevista sob os postulados teóricos de Schneuwly e Dolz (2004), que priorizam o trabalho com língua oral e escrita, objetivando o desenvolvimento textual a partir da internalização de gêneros de textos. Essa proposta aborda a temática variação semântico-lexical de uma localidade amazônica e foi aplicada numa turma de $9^{\circ}$ Ano do Ensino Fundamental de uma escola pública, com vistas a ressaltar a importância da variação linguística para a renovação dos procedimentos nas aulas de língua materna.
\end{abstract}

Palavras-chave: Língua Portuguesa. Estudo e Ensino. Gramática. Linguística.

\section{Cecília Maria Tavares Dias}

Mestra em Letras pela Univ.

Federal do Sul e Sudeste do Pará

- UNIFESSPA. Supervisora Escolar do Município de Tucuruí - PA e Professora da educação básica do Estado do Pará - PA.

Brasil

ceciliatavaresdias@gmail.com

\section{Para citar este artigo:}

DIAS, Cecília Maria Tavares. Leitura, gramática e escrita: tríade necessária para o ensino de Língua Portuguesa na construção do gênero entrevista com abordagem sobre variação linguística. Revista PerCursos, Florianópolis, v. 18, n.37, p. 130 - 150, maio/ago. 2017.

\section{DOI: $10.5965 / 1984724618372017130$}

http://dx.doi.org/10.5965/1984724618372017130 


\title{
Reading, grammar is written: necessary triad for the teaching of Portuguese Language in the construction of the interview gender with approach about linguistic variation
}

\begin{abstract}
This article aims to reflect on the teaching of grammar, reading and writing in the classes of Portuguese language; for that, it presents a proposal of didactic sequence (SD) with approaches about the production of the gender textual interview under the theoretical postulates of Schneuwly and Dolz (2004) that it prioritizes the work with oral and written language, aiming at the textual development starting from the internalization of gender of texts. This proposal approaches the theme semantic-lexical variation of an Amazonian location and it was applied in a group of 9 th Year of the Elementary School of a public school, with views to emphasize the importance of the linguistic variation for the renewal of the procedures in the classes of maternal language.
\end{abstract}

Keywords: Portuguese Language. Study and Teaching. Grammar. Linguistics. 


\section{Introdução}

Não existe língua sem gramática e todas as línguas apresentam variedades. Convém mencionarmos essa afirmação não apenas para refletirmos sobre a estrutura de uma língua e sua diversidade, mas pela necessidade de as escolas trabalharem a gramática nas aulas de língua portuguesa. No entanto, havemos de ressaltar que é necessário ensinarmos gramática, mas não da forma como o ensino é ainda ministrado em muitas escolas, onde alunos precisam decorar regras em vez de entendê-las e o emprego do já "cristalizado" certo e errado nas atividades tanto orais, quanto escritas, exercícios de classificação de termos usando nomenclaturas que não explicam nem têm relação com os conceitos, na maioria das vezes, entre outros. Sobre isso, sinaliza Antunes (2014, p. 15): “existe uma ilusão de que o ensino metalinguístico da gramática por generalizações e nomenclaturas pode levar o aluno ao uso social da língua". Para tanto, essa forma "desgastante" de se trabalhar com a gramática, não garante aos alunos uma aprendizagem significativa, cujos saberes linguísticos sejam necessários para que tenham acesso à informação, bem como a uma efetiva participação no meio social. Os falantes da língua materna já possuem uma gramática internalizada, pois se expressam de variadas maneiras, o que falta, no entanto, é desenvolver a habilidade de empregar a língua adequando-a às diversas situações de uso, como se posiciona Perini:

qualquer falante de português possui um conhecimento implícito altamente elaborado da língua, muito embora não seja capaz de explicitar esse conhecimento [...]. Mesmo pessoas que nunca estudaram gramática chegam a um conhecimento implícito perfeitamente adequado da língua. (PERINI, 1996 p. 124).

Segundo essa visão, convém refletirmos sobre o uso da gramática e a necessidade de trabalharmos sob uma nova perspectiva de reflexão sobre a língua em oposição ao ensino tradicional - abordagem na qual, de acordo com Mendonça (2006), certos aspectos da língua necessitam de uma orientação mais sistemática e normativa, para que os alunos possam dominá-los e ampliar cada vez mais sua capacidade de leitura, compreensão e interpretação dos textos lidos, para que sua habilidade linguística seja 
produtiva e eficaz. Por isso abordarmos, neste trabalho, a importância de a escola trabalhar os gêneros textuais, bem como, considerações a respeito da relação entre língua, gramática e escrita. Por conseguinte, apresentamos uma sequência didática sobre a produção do gênero textual entrevista, cujo texto produzido pelos alunos serviu de fonte diagnóstica para investigarmos avanços e dificuldades tanto na escrita quanto nas estratégias discursivas. Assim, a escrita do aluno passará a ter significado para as suas práticas diárias, pois a associação entre teoria e prática, mediada pelo docente, possibilitará a observação de dados da língua e a reflexão sobre o exercício da escrita.

a prática de análise linguística assume um status teórico-metodológico: teórico, porque constitui um conceito que remete a uma forma de observar dados da língua, apoiada em uma teoria; metodológico, porque é utilizado na sala de aula como um recurso para o ensino reflexivo da escrita. (BEZERRA; REINALDO, 2013, p. 14)

Dessa forma, o aluno passará a refletir sobre a construção dos seus textos, alicerçados por atividades que refletem dados da língua.

\section{Relação leitura x escrita x gramática}

Reiterando o uso da língua, empregar a linguagem, adequadamente, em determinadas situações, ainda é um grande desafio para muitos usuários de língua portuguesa, dada às dificuldades encontradas no ensino da língua nas escolas, uma vez que a gramática vem sendo usada de forma equivocada, ao longo dos tempos.

No entanto, sabemos que as pessoas conhecem a gramática de sua língua, mesmo não sabendo todas as regras da gramática normativa, ou seja, porque já se comunicam no dia a dia, porém isso nem sempre ocorre de forma competente, comunicativamente. Por isso, é necessário que o ensino de gramática deva estar voltado para a realidade do educando, todavia não na perspectiva do certo e do errado, como ocorre na abordagem tradicional, mas para a partir de sua experiência, ampliar seu horizonte de expectativas, desempenhando as diversas formas de se expressar em sociedade. Como diz Antunes 
(2014, p. 24): "A gramática se constitui pelos falantes de uma língua em suas interações." Mais além, a autora parte do pressuposto de que o ensino de gramática deve ser prazeroso ao aluno, já que tudo o que nos rodeia está relacionado com a linguagem.

É preciso, portanto, que mostremos ao aluno contextos em que o educando possa escolher entre uma forma e outra, ampliando todas as competências que a atividade verbal prevê e não apenas preparar o aluno para provas seletivas, mas para dela fazer uso, de forma competente. Assim, para que o aluno atinja o grau de letramento desejado e domine a variedade padrão, tanto oral quanto escrita, sem, no entanto, desprestigiar os outros tipos de variedade, é preciso que a escola proporcione uma nova forma de ensinar a língua materna, em que se proponham atividades que explorem a oralidade, a escrita e a leitura como práticas efetivas a partir da produção de gêneros textuais de uso real pois a relação leitura, escrita e gramática se completam quando se desenvolve, no aluno, a capacidade de descobrir caminhos que possibilitem tornar-se crítico e consciente para que compreenda o que lê e se faça entender por meio da escrita. Nessa perspectiva, é necessário que trabalhemos a leitura não somente para extrair dos textos aspectos gramaticais descontextualizados, mas com a finalidade de tornar os estudantes leitores proficientes, assim como, torná-la um objeto de aprendizagem que tenha sentido para a vida do aluno como referendam os PCN:

Como se trata de uma prática social complexa, se a escola pretende converter a leitura em objeto de aprendizagem deve preservar sua natureza e sua complexidade, sem descaracterizá-la. Isso significa trabalhar com a diversidade de textos e de combinações entre eles. Significa trabalhar com a diversidade de objetivos e modalidades que caracterizam a leitura, ou seja, os diferentes "para quês" — resolver um problema prático, informar-se, divertir-se, estudar, escrever ou revisar o próprio texto - e com as diferentes formas de leitura em função de diferentes objetivos e gêneros: ler buscando as informações relevantes, ou o significado implícito nas entrelinhas, ou dados para a solução de um problema. (BRASIL, 1997, p. 41)

Por isso, é fundamental que desenvolvamos a prática de leitura constante, na sala de aula, aproximando e familiarizando os alunos com os textos. Assim, criamos condição favorável para o desenvolvimento de uma leitura fluente e para a produção de textos, 
pois a leitura é alimento para a escrita, desse modo, para que o educando produza um bom texto, precisa ler textos de variados gêneros e que circulam em diferentes suportes. Com relação aos conteúdos gramaticais, é sabido que o uso da gramática prescritiva na sala de aula com ênfase no emprego de longas listas classificatórias das classes de palavras, por exemplo, sem um objetivo concreto, não contribui para uma aprendizagem eficiente, o que no dizer de Antunes (2014), a prescritividade reduz a gramática à norma e o entendimento da língua a seu componente gramatical.

Compreendemos, no entanto, que é necessário que se ensine a gramática na sala de aula, pois ela sempre será um componente importante para diversas situações de produção como a escrita de um texto que prime por um arcabouço linguístico formal, em que o aluno precisa conhecer e aplicar a sintaxe de concordância e regência, por exemplo. Entretanto, esse ensino precisa ser dinamizado, numa vertente desapegada do tradicional, ou seja, numa concepção que facilite o processo de ampliação das possibilidades do uso da língua. Assim postula Franchi (1987), após uma leitura crítica da gramática escolar:

Tem razão, pois, quem rejeita a gramática, quando se perde esta dimensão criadora e se esvazia o estudo gramatical de qualquer sentido pela desconexão entre seus objetivos e os objetivos de uma prática da linguagem em um contexto vital. Também porque somente se aprende a gramática, quando relacionada a uma vivência rica da língua materna, quando construída pelo aluno como resultado de seu próprio modo de operar com as expressões e sobre as expressões, quando os fatos da língua são fatos de um trabalho efetivo e não exemplos descolados da vida. (FRANCHI, 1987, p. 26)

Nessa perspectiva, convém que o trabalho com a gramática, nas aulas de língua portuguesa, possibilite a inserção do aluno a operar as expressões da língua relacionadas à vivência diária, ou seja, que o ensino tenha significado para a vida do educando. 


\section{Breves considerações sobre gêneros textuais}

Falar de gênero textual significa ressaltar que, ao longo de toda a história, o homem relaciona-se com a linguagem, pois o gênero textual é a forma como a língua é empregada nos textos em suas diversas situações de comunicação, o que para Marcuschi (2002), resulta do trabalho coletivo e contribui para ordenar e estabilizar as atividades comunicativas diárias, comprovando também que os gêneros textuais surgem, se situam e se integram, funcionalmente, nas culturas em que ocorrem. Nesse sentido, convivemos com uma diversidade de gêneros, cujas unidades são definidas por seus conteúdos, suas propriedades funcionais, estilo e composição organizados em razão do objetivo que cumprem na situação comunicativa. Assim, afirma Marcuschi apud Signorini:

O gênero tem existência concreta expressa em designações diversas, constituindo, em princípio, conjuntos abertos. Podem ser exemplificados em textos orais e escritos tais como: telefonema, sermão, carta comercial, carta pessoal, índice remissivo, romance, cantiga de ninar, lista de compras, publicidade, cardápio, bilhete, reportagem jornalística, aula expositiva, debate, notícia jornalística, horóscopo, receita culinária, bula de remédio, fofoca, confissão, entrevista televisiva, inquirição policial, email, artigo científico, tirinha de jornal, piada, instrução de uso, outdoor, etc. (MARCUSCHI; apud SIGNORINI, 2001, p.42-43)

Como vemos, para Marcuschi (2001), o gênero (também designado gênero do discurso) é uma forma textual concretamente realizada e encontrada como texto empírico, materializado. A língua, compreendida dessa maneira, é dinâmica e passa por inúmeras transformações, de acordo com as necessidades de seus falantes, daí, os gêneros textuais também acompanharem, simultaneamente, essas transformações.

Dessa forma, entendemos que é muito importante que trabalhemos os gêneros textuais, de acordo com a necessidade da turma, pois é expressiva a quantidade de estudantes que apresentam muitas dificuldades na leitura, compreensão e interpretação de textos, assim como na comunicação escrita. Por isso, o desenvolvimento de atividades envolvendo a produção de gêneros textuais orais e escritos constitui-se uma ferramenta 
indispensável ao aprimoramento da leitura e da escrita. Sobre isso, postulam Köche, Boff e Marinello (2012):

O aprimoramento da leitura e da escrita é o principal objetivo das aulas de Língua Portuguesa, e se concretiza através do desenvolvimento das habilidades de compreensão, interpretação e produção de gêneros textuais de circulação social. Assim, o eixo norteador do ensino de língua é o gênero enquanto unidade comunicativa, e o foco de ensino são suas características, a situação específica de produção, o tipo de informação que veicula, o destinatário almejado, e a finalidade da interlocução. (KÖCHE; MARINELLO; BOFF; 2012 p.11)

É preciso, portanto, que nas aulas de Língua Portuguesa, seja trabalhada a prática da produção de diversos gêneros textuais. Por isso, cabem ao professor de língua materna desenvolver nos alunos, comportamentos leitores e escritores, proporcionandoIhes estratégias que levem à escrita, considerando as características textuais e discursivas do gênero, em estudo. Nessa perspectiva, abordaremos nesse trabalho, o gênero textual entrevista, o qual possui uma finalidade em si mesmo - a informação, que trata da interação entre os interlocutores, representados na pessoa do entrevistador e do entrevistado, em que o primeiro relata suas experiências e conhecimentos acerca de um determinado assunto de acordo com os questionamentos previamente elaborados pelo segundo. Vale salientar que, além desses requisitos, é primordial - a busca incessante pelo conhecimento com vistas à amplitude de nossa visão de mundo. No caso do entrevistador, é imprescindível que, antes de tudo, ele tenha domínio do assunto, de modo a elaborar um roteiro de perguntas consideradas significativas, buscando, assim, alcançar os seus objetivos propostos.

\section{Sequência didática}

A prática da produção textual oral e escrita contribui para o exercício da cidadania. Nesse sentido, entendemos que a perspectiva pragmática, em que a linguagem é concebida como criação de sentido da origem à comunicação, possibilita a interação social entre sujeitos. Por isso, comungamos da ideia de que para a realização 
de uma produção textual, nada mais relevante do que trabalharmos com uma sequência didática (SD), que conforme Schneuwly e Dolz (2004), trata-se de um conjunto de atividades didáticas organizadas, de maneira sistemática, em torno de um gênero textual oral ou escrito. Para esses autores, a estrutura de uma SD para uma produção escrita deve contemplar a produção inicial que visa avaliar as capacidades iniciais e identificar as dificuldades dos alunos para a produção do gênero, os módulos em que eles realizam várias atividades para se apropriarem do gênero textual em questão e uma produção final, após realizarem uma avaliação, bem como, uma revisão de suas produções iniciais, guiados por uma lista de constatação.

Desse modo, dado um trabalho de pesquisa-ação que desenvolvemos numa escola de ensino fundamental de Tucuruí-PA, foi necessária a aplicação de uma SD para o trabalho com a produção textual. Nela, foram abordados procedimentos de como produziríamos uma entrevista sobre a variação lexical desse município amazônico, lugar que passou por um fluxo migratório muito grande com a construção da UHT (Usina Hidrelétrica de Tucuruí). Com essa pesquisa, buscamos ressaltar a importância dos dialetos e registros e suas contribuições para a formação da identidade cultural do município, bem como contribuir para a renovação dos procedimentos em sala de aula, voltados para o ensino do léxico, no sentido de valorizar tanto a língua culta, quanto a variação linguística dos alunos, além de promover a ampliação do vocabulário. Para tanto, foi trabalhado o gênero textual entrevista, com o objetivo de desenvolver, nos alunos, as habilidades necessárias para a conversa com os informantes.

Esta proposta de sequência didática, cuja tônica é como trabalhar a língua portuguesa na sala de aula, com vistas à construção dos conteúdos numa associação em que leitura, gramática e escrita contribuem, significativamente, para a produção do gênero textual entrevista, foi trabalhada na Escola Maria Fernandes de Medeiros Alves, numa turma de $9^{\circ}$ ano em 12 encontros, sendo duas aulas a cada encontro, perfazendo, portanto, um total de 24 aulas. 


\section{Proposta de sequência didática: entrevista}

Objetivo geral: Produzir o gênero textual Entrevista.

\section{Objetivos específicos:}

- Proporcionar ao aluno o contato com a leitura de vários textos sobre entrevista;

- $\quad$ Conhecer o gênero entrevista - constituição e funcionamento;

- Ampliar capacidade dos alunos de ler entrevistas;

- Reconhecer algumas das características e funções de uma entrevista;

- Aprimorar a fala em situação de comunicação oral formal;

- $\quad$ Participar de uma situação de comunicação oral formal;

- Conscientizar os alunos dos problemas diversos que a entrevista apresenta;

- Definir o que significam sequência didática e lista de constatações;

- Avaliar a capacidade de escrita de entrevista dos alunos, tendo como base a lista de constatações do gênero;

- Produzir uma linguagem unificadora do gênero em estudo.

\section{A apresentação da situação - (02 aulas)}

Essa é uma etapa muito importante que objetiva apresentar aos alunos o projeto de prática de linguagem a ser realizado na produção final. Assim, iniciamos a aula, fazendo perguntas aos alunos, do tipo: "Vocês já assistiram a alguma entrevista na televisão?”, “Quem era o entrevistado?”, “E o entrevistador?”, “Vocês já leram alguma entrevista?", entre outras que poderiam surgir, no momento. Depois disso, falamos sobre o objetivo desse gênero, nessa turma de $9^{\circ}$ Ano, que foi o de produzir uma entrevista sobre a variação lexical dos moradores de Tucuruí, para, assim, ampliar o conhecimento que a turma tinha sobre esse gênero. Para isso, antes de lermos/vermos/ouvirmos uma entrevista com os alunos, foi preciso que levantássemos os conhecimentos prévios da turma a respeito dos portadores impressos e orais nos quais encontramos as entrevistas (jornal, revista, site, programa de TV e rádio, entre outros), sobre o gênero em si 
(entrevista), que aparece sob as formas oral e escrita, bem como, sobre os entrevistados que seriam escolhidos.

Começamos, portanto, perguntando aos alunos em qual portador lemos e ouvimos entrevistas, com o cuidado de complementar as respostas que aparecessem. Perguntamos se já leram ou ouviram entrevistas, onde e com quem. Questionamos sobre as situações em que costumamos ler/ver/ouvir esse tipo de gênero e esclarecemos que as entrevistas também podem ser encontradas em sites na internet. Desse modo, a finalidade era que os alunos, sabendo onde podiam encontrar uma entrevista e seu uso social, pudessem antecipar seu conteúdo informativo.

Nessa apresentação, também foram abordados os elementos básicos que norteiam a produção desse gênero, assim como os tipos de entrevistas, características e a lista de constatações. Neste sentido, é importante que o professor deixe claro aos estudantes as seguintes questões que compreendem o problema de comunicação:

Apresentação da situação comunicativa: Produzir uma entrevista para ser postada no blog da escola e/ou mural.

Gênero: Entrevista

Lugar físico/momento de produção: Sala de aula/durante as aulas ministradas.

Emissor: Alunos do $9^{\circ}$ Ano do Ensino Fundamental.

Receptor: Professor (a)

Lugar social: Escola Maria Fernandes de Medeiros Alves

Enunciador: Alunos

Destinatário: Professor, comunidade escolar e depois, o blog da turma e/ou mural da escola.

\section{Atividade I}

Número de aulas: 02 aulas

Nessa etapa, levamos os alunos ao laboratório de informática (agendado anteriormente), o qual possuía poucos computadores funcionando e com acesso à 
internet para assistirmos ao vídeo "O gênero entrevista", que é um exemplo de uma entrevista na forma oral. ${ }^{1}$

\section{Atividade II}

Número de aulas: 02 aulas

Nessa atividade, abordamos, por meio de texto escrito, os elementos fundamentais de uma entrevista, tais como, a definição desse gênero, a elaboração de um roteiro, os tipos de entrevista, a forma como se deve concluí-la, entre outros. ${ }^{2}$

\section{Atividade III}

Número de aulas: 02 aulas

Como a temática tratava do tema variação linguística, apresentamos como recurso de leitura, as seguintes entrevistas escritas: “Entrevista com professor Ataliba Castilho, do Departamento de Letras Clássicas e Vernáculas, a respeito do conceito de Língua Viva e Variantes Linguísticas"3 e uma questão comentada da prova do ENEM (Exame Nacional do Ensino Médio) 2012 que aborda uma entrevista com o professor Marcos Bagno.

\section{Atividade IV}

Número de aulas: 02 aulas

Após o roteiro pronto, combinamos com a turma a melhor data para a realização da produção inicial. Em seguida, definimos o que precisaria ocorrer na entrevista: quem faria as perguntas sobre os itens lexicais que apareceriam de forma característica na fala dos moradores de Tucuruí; como seria a gravação e quem ficaria responsável por essa

\footnotetext{
${ }^{1}$ Esse vídeo está disponível em: < http://portaldoprofessor.mec.gov.br/fichaTecnicaAula.html?aula=18638>.

2 Esse material selecionado ("instrumento de pesquisa social: entrevista"), encontra-se disponível em: $<$ www.uems.br/propp/conteudopos/AAE/entrevista $>$.

${ }^{3}$ Material disponível em: <comunicacao.fflch.usp.br/node/646>.
} 
tarefa. Dessa forma, dividimos a turma em duplas, sendo que cada dupla elaborou as questões por áreas semânticas, referentes a acidentes geográficos, fenômenos atmosféricos, astros e tempo, atividades agro-pastoris, fauna, corpo humano, ciclos da vida, convívio e comportamento social, religião e crenças, jogos e diversões infantis, habitação, alimentação e cozinha, vestuário e acessórios e sobre a vida urbana. Isso de acordo com o questionário do Projeto Atlas Linguístico do Brasil (ALiB), que se fundamenta nos princípios gerais da Geolinguística contemporânea, prioriza a variação espacial ou diatópica e está atento às implicações de natureza social. Aqui representamos apenas um campo semântico (o primeiro) do questionário piloto de base semânticolexical do Estado do Pará/1997 (contém 15 campos) que foi elaborado tendo como base a primeira versão do questionário do ALIB e nós utilizamo-lo conforme a realidade do município.

\section{I - Natureza e Acidentes Geográficos}

\section{TIPOS DE TERRENO}

1- Que tipo de terreno, terra você conhece? Que nome se dá aqui para o terreno ou a terra que fica próximo ao rio?. E o que vocês podem plantar neste terreno?

CÓRREGO***/RIO PEQUENO/ FURO/IGARAPÉ OU BRAÇO DE RIO

2- Como vocês chamam aqui um rio pequeno, de uns dois metros de largura?

TRECHO DO RIO ONDE A ÁGUA CORRE COM MAIS FORÇA/CORRENTEZA

3- No rio tem um lugar onde a água corre com muita força. Como vocês chamam para isso?

\section{MARGEM}

4- E para o lado do rio, que nome que vocês dão para o lado do rio?

\section{PONTE}

5- E para atravessar o rio, o igarapé, a gente tem que passar por cima de quê?

\section{PINGUELA ***}

6- Tronco, pedaço de pau ou tábua que serve para passar por cima de um... (item no. 02)

NASCENTE DE RIO

7- Que nome que dão aqui para o lugar onde o rio nasce? 
FOZ

8- ...o lugar onde o rio termina ou encontra com outro rio?

\section{REDEMOINHO (DE ÁGUA)}

9- Muitas vezes, num rio, a água começa a girar, formando um buraco na água que puxa para baixo. Como se chama isto?

\section{LAGOA}

10- Tem um lugar onde a água não é muito funda, então junta a água e os patinhos gostam de nadar?

ILHA

11- Às vezes o rio rodeia um pedaço ou monte de terra, como se chama para isso?

MANGUE

12- E aquele terreno úmido onde a gente, quando passa, pode até afundar os pés?

POÇA D'ÁGUA

13- Quando chove, fica um pouquinho de água aqui outro pouquinho ali. Que nome que dão para esse pouquinho de água da chuva que fica parada?

AREIA

14- E aquela terra meio branca que serve para fazer construção?

ONDA DE RIO***/ONDA OU BANZEIRO

15- ...o movimento da água do rio (imitar o balanço das águas)?

\section{ONDA DE MAR***/ONDA (só na região do salgado)}

16- Como se chama o movimento da água do mar?

\section{TERRA EMUDECIDA PELA CHUVA***/MOLHADA ${ }^{4}$}

$17-$

\section{LAGO}

18 - Que nome se dá para um lugar que tem água, mas não é lagoa, nem rio e diz-se que lá mora o sapo?

Para esse exercício, apresentamos para os alunos esse questionário semânticolexical e explicamos que as perguntas elaboradas por eles, não deveriam ser tais quais às

4 O Questionário piloto de base semântico-lexical do Estado do Pará/1997 apresenta apenas a sugestão de resposta, nesse quesito. 
do documento, mas de acordo com a tônica e o formato de como se produz uma entrevista. Assim, essa entrevista foi uma possibilidade metodológica para induzirmos ou provocarmos amostras da variação léxica em estudo, nesse caso, a linguagem de Tucuruí.

\title{
Produção do texto inicial
}

Número de aulas: 03 aulas

Essa produção foi uma atividade na, sala de aula, na qual uma dupla de alunos entrevistou outra, sobre a variação lexical da localidade. Nesse dia, verificamos se todos os instrumentos necessários para a realização da entrevista estavam disponíveis: filmadora/gravador, pilhas extras e roteiro da entrevista. Os alunos fizeram as perguntas e estavam cientes da ordem em que deveriam se pronunciar. No momento da entrevista, fizemos perguntas não previstas no roteiro e sinalizamos para o grupo no caso de repetição de perguntas que ocorreram. Fizemos isso com cuidado para que fosse apenas uma intervenção pontual e a entrevista fosse realizada pelos alunos.

Essa primeira produção, na sala de aula, deu-se de forma simplificada, pois foi um treino para o aluno, que, aos poucos, se foi familiarizando com o gênero.

\begin{abstract}
A produção inicial pode ser simplificada, ou somente dirigida à turma, ou, ainda, a um destinatário fictício. Por exemplo, uma primeira entrevista pode ser realizada com um colega de classe; ou alguns alunos podem tentar realizar uma primeira exposição com uma preparação mínima sobre um tema que já dominam, ou sobre um mesmo tema elaborado por toda a classe. (SCHNEUWLY; DOLZ, 2004, p. 86)
\end{abstract}

Dessa forma, essa produção abordou algumas perguntas sobre a temática proposta, que tratava de variação linguística, após as aulas. que trataram desse assunto. Essa fase da produção inicial é a essência da avaliação formativa ${ }^{5}$ porque definirá para o professor o ponto preciso no qual ele pode realizar a intervenção e para o aluno, o caminho que terá de percorrer.

\footnotetext{
${ }^{5}$ Avaliação cuja finalidade é a melhoria da aprendizagem em curso, mediante processo de regulação permanente.
} 


\section{Módulo I}

\section{Número de aulas: 03 aulas}

Após essa produção, no primeiro momento, conversamos com a turma sobre a escuta das entrevistas orais, preparando-a para o respeito e a valorização das falas dos alunos. E noutro momento, socializamos as leituras dos textos produzidos por eles, em que uma dupla leu a de outra dupla. Feito isso, juntos analisamos alguns problemas, que ocorreram, como na seguinte situação:

Entrevistador 1 (E1) - Bom dia (olhando para a câmera), hoje iremos entrevistar dona Maria do Socorro, moradora do bairro Alto Alegre, que fica próximo a nossa escola.

Entrevistador 2 (E2) - Bom , quanto tempo você mora em Tucuruí ? (...)

E2 - “Tá”, e você quando veio pra cá, achou que as pessoas falavam diferente?

Em relação ao que ocorreu quanto a esse estilo, explicamos aos alunos que, embora eles tenham tentado empregar a formalidade, o E2 fez uso de um marcador conversacional informal ("tá"), no início da segunda pergunta que fez à pessoa entrevistada. Isso mostra que o aluno/entrevistador transitou entre a modalidade formal e a informal da língua, precisando, portanto, que explicássemos o que são marcadores conversacionais, apresentando à turma vários exemplos e, deixando claro, que esses são próprios da modalidade oral informal. No entanto, no caso da entrevista, embora seja um gênero também oral, em que dependendo da situação comunicativa, como esse trabalho que visava à produção de um gênero textual que pertence à esfera social (mas que pode ser trabalhado na escola), deverá primar pelo emprego da língua culta, uma vez que na estrutura curricular da disciplina Língua Portuguesa, o ensino de gramática, sobretudo, o produtivo, alicerça o desenvolvimento da competência comunicativa do educando, pois não desconsidera seus conhecimentos linguísticos pré-existentes, assim como, desenvolve as habilidades linguísticas, incluindo o domínio da norma culta e o da modalidade escrita. Desse modo, apresentamos exemplos de entrevistas escritas contendo marcadores conversacionais e pedimos aos alunos que os identificassem e 
reescrevessem os textos retirando os que, de alguma forma, “empobreciam” a pretensão de um texto culto.

\section{Módulo II: Retextualização da produção}

Número de aulas: 02 aulas

A produção textual dos alunos apresentou alguns problemas com relação à pontuação, visto que a passagem do texto oral para o escrito (retextualização), implica o emprego do discurso direto, em que são empregados, geralmente, o travessão, o ponto de interrogação nas perguntas diretas, entre outras ocorrências, pois retextualizar o texto oral para o escrito, dá mais trabalho, uma vez que além das perguntas e respostas, nessa modalidade, temos acesso a outros tipos de informações como: gestos, entonação da voz, olhares, rubor da pele, entre outros, o que requer do produtor de textos conhecimentos gramaticais para empregá-los, adequadamente, na produção do texto. Assim, aplicamos à turma uma atividade que consistia em proporcionar o conhecimento da função dos sinais de pontuação, exemplificando-os em trechos de entrevistas em aula expositiva sobre o assunto ${ }^{6}$ e mostramos no fragmento da entrevista como são utilizados esses sinais, sobretudo, o travessão, os dois pontos e o ponto de interrogação, sinais muito presentes na constituição do gênero entrevista.

\section{Módulo III: A reescrita da produção inicial}

Número de aulas: 03 aulas

Após a feitura dos textos pelos alunos, proporcionamos momentos de revisão do texto para que eles se habituassem a olhar a primeira versão de seu texto como um produto inacabado, provisório, que pode ser revisado e reescrito quantas vezes forem necessárias (ANTUNES, 2003), pois é a partir das revisões efetuadas no texto elaborado

\footnotetext{
6 Utilizamos alguns slides disponíveis em: $\quad$ estacio. webaula.com.br/Cursos/up0106/material.../ppt/arq/aula_9>.
} 
pelo aluno, que surge a reescrita. Essa reescrita deveria ter como base a seguinte lista de constatações:

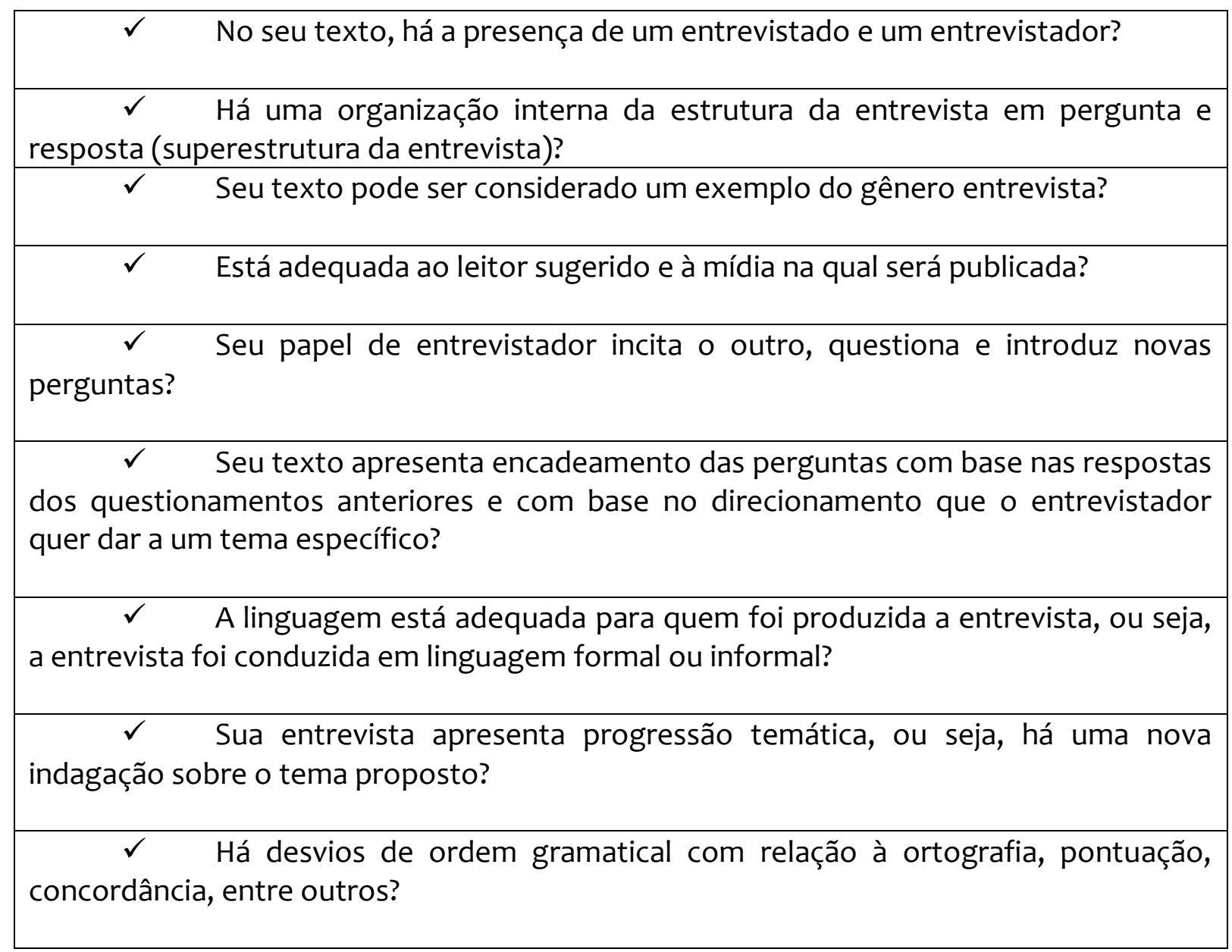

Ressaltamos a importância de atuarmos como mediadores nesse processo, porque a lista de constatações é uma ferramenta didática que regula não só a aprendizagem do aluno, mas também as ações do docente. Desse modo, uma das correções que poderá contribuir para o processo da reescrita será o professor corrigir o texto, utilizando a escrita de bilhetes textual-interativos, após o corpo textual, que para Ruiz (2010), é uma estratégia muito válida, sobretudo, quando o professor pretende mostrar problemas de ordem global, que aparecem no conteúdo do texto. Assim, é possível a interação entre o professor e aluno no que se refere aos avanços no trabalho de produção do aluno, pois a partir da devolução do texto ao discente, inicia-se o exercício de reescrita do texto. 


\section{Módulo IV - Verificação da aprendizagem: avaliação formativa}

Número de aulas: 02 aulas

A avaliação foi proposta com base na participação do aluno ao longo de toda produção do gênero entrevista. Nesse sentido, avaliamos a capacidade de os alunos trabalharem em parceria, bem como sua criatividade e coerência na elaboração de questões e o trabalho com a produção final da entrevista. Em síntese: o trabalho em sequência didática proposto foi julgado em cada etapa de aprendizagem e na realização da nova entrevista. Além do mais, orientamos os alunos em relação à publicação das entrevistas, ou seja, eles se prepararam para publicá-las, conforme decisão anterior quanto ao local de circulação do gênero, que foi um mural exposto na própria escola para apreciação pela comunidade. Isso porque o blog estava desativado e a referida escola atende a uma clientela de muitos alunos carentes, em que poucos têm acesso à internet, por isso, a apresentação em mural divulgou melhor o trabalho para a comunidade escolar.

\section{Produção final}

Número de aulas: 03 aulas

Essa é a fase final que trata sobre o controle do processo da aprendizagem, pois permite ao aluno colocar em prática as noções e os instrumentos elaborados separadamente nos módulos, ou seja, o que construiu nos módulos, e a reflexão sobre o que aprendeu e o que resta aprender, por conseguinte, serviu para o educando como um instrumento para avaliar e revisar o seu texto, definindo ou não a necessidade de reescrever a sua produção. Em se tratando da nossa ação desenvolvida, permitiu-nos fazer uma avaliação formativa para planejarmos um próximo trabalho. 


\section{Considerações finais}

A articulação entre leitura, produção textual e análise de dados da língua, quando desenvolvida de forma dinâmica e produtiva, contribui, significativamente, para a inserção do aluno no mundo da escrita. Dessa forma, trabalhar com a teoria dos gêneros discursivos permite ao aluno atentar para os diferentes aspectos que dizem respeito à produção de um texto, o que o ajudará no desenvolvimento de sua competência discursiva.

Refletindo sobre isso, foi que relatamos, nesse trabalho, uma proposta de sequência didática, cujas atividades foram alicerçadas num ensino de gramática produtivo (em que procuramos trabalhar a lacuna que existe entre a variedade trazida de casa pelo aluno e a norma culta, no sentido de incluí-lo socialmente), aliado à leitura de diversos textos sobre a temática proposta, os quais proporcionaram aos discentes o ensino do gênero textual entrevista, numa concepção que os instrumentalizou a desenvolverem habilidades que favorecem o domínio dessa prática, bem como permitiu aos aprendizes o desenvolvimento de capacidades de linguagem que poderão ser úteis para o ensino de outros gêneros textuais, ou seja, por meio desse trabalho pedagógico com os gêneros orais presentes na sociedade, as aulas serão mais prazerosas e significativas, visto que o aluno será preparado para o uso dessa competência nas diversas esferas da comunicação. Considerando uma atividade produtiva, esse trabalho vivenciado na Escola Maria Fernandes poderá servir como uma contribuição nas aulas de língua portuguesa em ambientes escolares, onde é imprescindível a mediação dos docentes, que a usarão também para avaliar a sua prática na sala de aula.

Além do mais, esperamos contribuir, positivamente, para a aquisição de novos conhecimentos, ampliação de repertório, previsão de materiais para as aulas e novas possibilidades de trabalho coletivo, em que professor e alunos, juntos, ampliarão seus horizontes na busca de uma melhor aprendizagem da língua materna.

\section{Referências}

ANTUNES, Irandé. Aula de português: encontro e interação. São Paulo, Parábola, 2003d. 
Gramática contextualizada: limpando o pó das ideias. $1^{\text {a }}$ ed. São Paulo:

Parábola Editorial, 2014.

BEZERRA, Maria Auxiliadora; REINALDO, Maria Augusta. Análise linguística: afinal, a que se refere? São Paulo: Cortez, 2013.

BRASIL. Ministério da Educação. Secretaria de Educação Fundamental. Parâmetros curriculares nacionais: primeiro e segundo ciclos do ensino fundamental: língua portuguesa. Brasília, MEC/SEF, 1997.

FRANCHI, Carlos. Criatividade e gramática: Trabalhos em linguística aplicada. Campinas, n.9, p. 5-45, 1987.

KÖCHE, Vanilda Salton; BOFF, Odete Maria Benetti.; MARINELLO, Adiane Fogali. Leitura e produção textual: gêneros textuais do argumentar e expor. 3.ed. Petrópolis; Rio de Janeiro: Vozes, 2012.

MARCUSCHI, Luiz Antônio. Gêneros textuais: definição e funcionalidade. In: DIONÍSIO, Angela Paiva.; MACHADO, Anna. Rachel.; BEZERRA, Maria Auxiliadora. (org.). Gêneros textuais \& ensino. $2^{\circ}$ ed. Rio de Janeiro: Lucerna, 2002

MENDONÇA, Márcia. Análise linguística no ensino médio: um novo olhar, um outro objeto. In: BUNZEN, Clecio; MENDONÇA, Márcia. Português no ensino Médio e formação do professor. São Paulo: Parábola Editorial, 2006. p. 109-226.

PERINI, Mário Alberto. Gramática descritiva do português. 2. ed. São Paulo: Ática, 1996.

RUIZ, Eliana Donaio. Como corrigir redações na escola. São Paulo: Contexto, 2010.

SCHNEUWLY, Bernard. \& DOLZ, Joaquim. Gêneros orais e escritos na escola. Tradução e organização Roxane Rojo e Glaís Sales Cordeiro. Campinas/SP: Mercado de Letras, 2004 